ROBUSTELLI, F., \& JARVIK, M. E. Retrograde amnesia from detention. Physiology \& Behavior, 1968, 3, 543-547.

WILCOXON, F., \& WILCOX, R. A. Some rapid approximate statistical procedures Lederle Laboratories, Pearl River, N.Y., 1964.
NOTE

1. This research was supported by USPHS Grant MH 05319 from the National Institute of Mental Health and an Interdepartmental Institute for Training in the Neurologic and $\mathrm{Be}$ havioral Sciences Grant 5T1 MH 6418.

\title{
Stimulus control of prey attack in naive rat snakes: A species duplication'
}

DALE D. MORRIS and MICHAELS. LOOP, 2 Division of Biological and Medical Research, Argonne National Laboratory, Argonne, Ill. 60439

Previously unfed, newborn rat snakes (Elaphe) were found to exhibit a greater response to prey-object extracts than to a distilled-water control stimulus. Response to the different prey-object extracts was not different. The results indicate that young rat snakes accept a wide variety of prey. objects-those normally eaten by the adult and prey of a convenient size.

G. M. Burghardt (1966) has demonstrated that newborn garter snakes (Thamnophis) can be induced to attack a cotton swab containing a chemical extract from the body surface of preferred prey. These previously unfed snakes at tempt to eat a swab dipped in worm extract but refused to attack similar swabs containing horsemeat extract or distilled water. Subsequent studies (Burghardt, 1967a) revealed a high correlation between the chemical extracts most stimulating to a young snake and the food items most commonly eaten by the adult under natural conditions. Burghardt (1967b) states, "The inexperienced snake somehow can recognize, on the basis of chemical stimuli alone, what it 'should' attack as a potential prey object."

A characteristic common to all species reported on by Burghardt is that they possess no specialized food-capturing talents. No species of poisonous snakes or constrictors have been studied. Snakes investigated thus far rely solely on the "seize and swallow" technique of prey capture. Modest size and the inability to kill prey prior to ingestion dictates the selection of prey that are small and incapable of injuring the snake. The question now arises, what of the species of snakes that as adults typically feed on large, potentially dangerous animals? For example, how will a 12-g rat snake respond to the chemical stimuli of prepared extract from a 140 -g rat?

\section{METHOD}

The 11 Ss were the offspring of an inter-race mating between a male Elaphe obsoleta quadrivittata from Southern Florida and a female Elaphe obsoleta obsoleta from Eastern Tennessee. The initial clutch contained 17 eggs, of which 14 hatched. Four of the newly hatched snakes were physically deformed, and three of these died shortly after hatching. The one surviving snake had a malformed eye and tail but was used in the study: At birth, the mean weight of the Ss was $12.1 \mathrm{~g}$.
The stimulus items were distilled water. goldfish (Carassius), frog (Rana), worm (Lumbricus), cotton rat (Sigmodon), laboratory white mouse (Strain CF No. 1/Anl), adult and baby deer mice (Peromyscus), baby domestic chick (Gallus), and grasshopper (Melanoplus). Preparation involved placing the whole stimulus prey-object in 50 -deg $\mathrm{C}$ water $(10 \mathrm{ml}$ per $1.5 \mathrm{~g}$ body weight) for $1 \mathrm{~min}$. The prey-object was removed and the remaining aqueous solution was then centrifuged at $2000 \mathrm{cps}$ for $10 \mathrm{~min}$ and refrigerated at $7.2 \mathrm{deg} \mathrm{C}$ until used.

The Ss were tested after their initial molt, which occurred approximately 13 days after birth. They were moved to individual plastic containers $12 \mathrm{~h}$ prior to testing. Illumination prior to and during the experiment was provided by $60-\mathrm{W}$ red lights. The time between stimulus presentations for each $S$ was $30 \mathrm{~min}$. For each trial, a cotton swab dipped in extract was placed $2 \mathrm{~cm}$ in front of the S's snout. If no attack occurred with in $30 \mathrm{sec}$, the swab was moved slowly forward until it touched the S's snout and then removed to $2 \mathrm{~cm}$. A single trial lasted $90 \mathrm{sec}$, during which the number of tongue flicks were counted. If an attack was made, the trial was terminated and the latency was recorded to the nearest second. The entire experiment lasted $5.5 \mathrm{~h}$. Each $\mathrm{S}$ received one presentation of each stimulus item, with stimuli presented in random order.

The effectiveness of stimulation by each extract was evaluated by using Burghardt's formula. This formula is the maximum number of tongue flicks emitted by any $S$ to any stimulus, plus the length of a single trial, minus the latency of the attack in seconds. If no attack occurred, the number of tongue flicks was taken as the stimulating value of the extract. The data were analyzed by nonparametric statistical methods since the assumptions of parametric methods were not met.

\section{RESULTS}

During the 110 trials only 10 at tacks were observed. The mean latency of these attacks was $40.2 \mathrm{sec}$. For the remaining 100 trials, the number of tongue flicks for a single trial ranged from 0 ( 18 trials) to 155 (2 trials). The mean tongue flick-attack score for each stimulus item is presented in Fig. 1. The three highest mean scores were elicited by cotton rat, fish, and laboratory mouse. Only these stimuli elicited more than one attack. One attack each was elicited by frog, worm, adult deer mouse, and baby deer mouse.

Since there appeared to be a difference in the level of responding as the testing progressed, a Walsh Test (Siegel, 1956) was performed to compare the mean response of each $S$ for each stimulus item on Trials $1-5 \mathrm{vs}$ Trials 6-10. The difference was found to be 


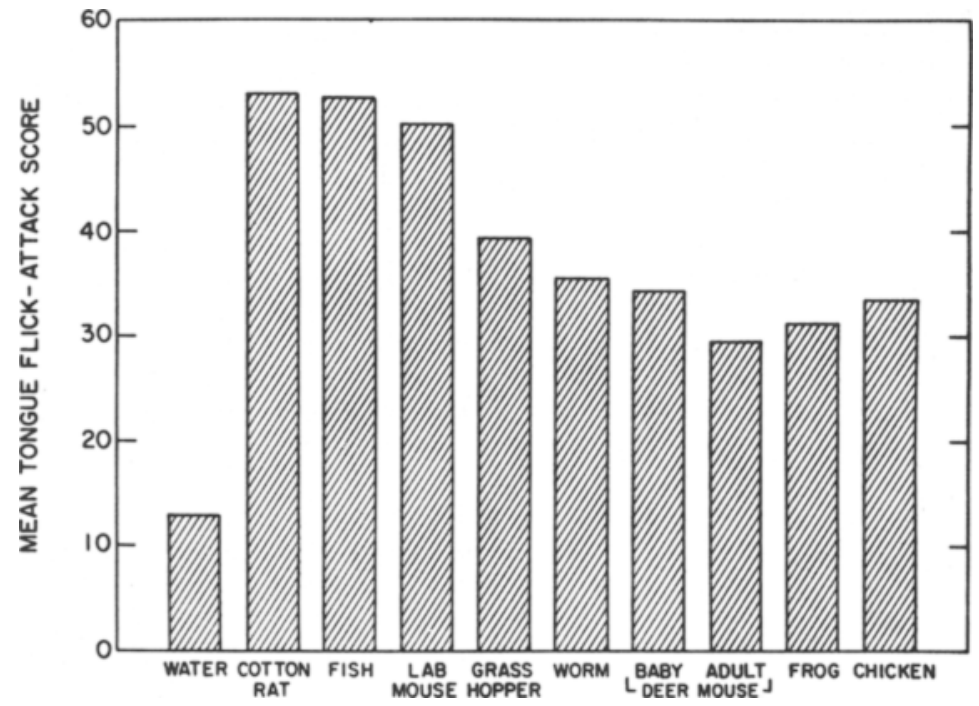

Fig. 1. The mean tongue flick-attack score for each stimulus item.

significant $(\mathrm{p}<0.01$, two-tailed). The response rate was higher for the first five trials.

The total number of responses for the 10 trials given each $\mathrm{S}$ also varied considerably. The range was from 63 to 1063 . Because of this variability, the data were normalized. A single S's score for each stimulus item was transformed to a per cent of that S's total score. The data were then analyzed by Friedman's two-way analysis of variance (Siegel, 1956), a nonparametric test for related samples. A first test was performed across all stimulus items. The difference was significant $(p<0.05)$. A second test was performed across all stimulus items with the exception of the control stimulus (distilled water). The difference was not significant $(0.50<p<0.70)$. It was concluded that the response to the prey-object ex tracts did not differ among themselves, and that the DISCUSSION worm. mean attack score in comparison to the other prey-object extracts. This suggests that if a "low" attack score is correlated with a food animal that was accepted, any stimulus receiving a higher attack score would also be accepted. Considering Burghardt's evaluation of the significance of an attack score, these results imply that a newborn Elaphe confronted with an adult cotton rat will attempt to eat it. It follows that all prey of the first category would be acceptable targets for the young rat snake. This conclusion seems unlikely. It seems equally improbable that a 6-ft adult Elaphe would waste its time devouring the excessive numbers of worms, grasshoppers, or fish required to satiate it.

The data indicate that young rat snakes enter the world accepting a wide variety of prey objects-those normally eaten by the adult and prey of a convenient size. Factors that may inhibit young snakes from attacking animals too large to be eaten remain undetermined. It is the authors' opinion, however, that size and/or the behavior of prey-objects would be a profitable variable to investigate.

Ey jar containing two Ss. The mouse was attacked by one of the Ss within $30 \mathrm{sec}$, in all cases. In three of the six jars, both of the Ss attempted to eat the young mouse.

The stimulus items can be separated into several categories: (1) prey frequently eaten by adult snakes but too large for juveniles, i.e., cotton rat, lab mouse, deer mouse, and chicken; (2) prey frequently eaten by adults and small enough for juveniles, i.e., baby deer mouse; and (3) prey not usually eaten by Elaphe yet small enough to be eaten by juveniles, i.e., grasshopper, fish, frog, and

Baby deer mice, which were accepted quite readily as a first meal, had a rather low

\section{REFERENCES}

BURGHARDT, G. M. Stimulus control of the prey attack response in naive garter snakes Psychonomic Science, 1966, 4, 37-38.

BURGHARDT, G. M. Chemical-cue preferences of inexperienced snakes: Comparative aspects. Science, 1967a, 157, 718-721.

BURGHARDT, G. M. Chemical perception in newborn snakes. Psychology Today, 1967b, August, 51-59.

SIEGEL, S. Nonparametric statistics for the behavioral sciences New York: McGraw-Hill, 1956. Pp. 83-87, 166-172. NOTES

1. Work supported by the U.S. A tomic Energy Commission.

2. Summer student aide, now a graduate student in the Department of Psychology at Florida State University, Tallahassee, Florida.

\section{ERRATUM}

DAVIS, JOEL L., \& THOMPSON, RICHARD F. Sensory preconditioning of cats in a shuttle box avoidance situation. Psychonomic Science, 1968, 13 (1), 37-38.--Due to an oversight by the authors, an error was made in the above paper. The second sentence of the second paragraph in the methods section should read "During this time the auditory stimulus was presented for $6 \mathrm{sec}$ with the light presented contiguously for the last $2 \mathrm{sec} .$. ." The italicized terms were incorrectly interchanged in the original paper. It, of course, would have been a "backward" sensory preconditioning situation, which was not the case. The authors are indebted to Dr. M. E. Bitterman for calling the error to their attention. 